Please do not remove this page

RMIT

UNIVERSITY

\title{
Thermal comfort properties of wool and polyester/wool woven fabrics dyed in black
}

Tashkandi, Salwa; Fergusson, Stanley Mac; Wang, Lijing; Kanesalingam, Sinnappoo

https://researchrepository.rmit.edu.au/esploro/outputs/9921859793201341/filesAndLinks?institution=61RMIT_INST\&index=null

Tashkandi, S., Fergusson, S. M., Wang, L., \& Kanesalingam, S. (2013). Thermal comfort properties of wool and polyester/wool woven fabrics dyed in black. Journal of Fiber Bioengineering and Informatics, 6(3), 265-275. https://doi.org/10.3993/jfbi09201304

Document Version: Published Version

Published Version: https://doi.org/10.3993/jfbi09201304

Repository homepage: https://researchrepository.rmit.edu.au

(c) 2013 Binary Information Press \& Textile Bioengineering and Informatics Society

Downloaded On 2023/04/26 20:48:14 +1000 
Thank you for downloading this document from the RMIT Research Repository.

The RMIT Research Repository is an open access database showcasing the research outputs of RMIT University researchers.

RMIT Research Repository: http://researchbank.rmit.edu.au/

\section{Citation:}

Tashkandi, S, Fergusson, S, Wang, L and Kanesalingam, S 2013, 'Thermal comfort properties of wool and polyester/wool woven fabrics dyed in black', Journal of Fiber Bioengineering and Informatics, vol. 6, no. 3, pp. 265-275.

See this record in the RMIT Research Repository at:

http://researchbank.rmit.edu.au/view/rmit:24012

Version: Published Version

Copyright Statement: (c) 2013 Binary Information Press \& Textile Bioengineering and Informatics Society

Link to Published Version:

http://dx.doi.org/10.3993/jfbi09201304 


\title{
Thermal Comfort Properties of Wool and Polyester/Wool Woven Fabrics Dyed in Black
}

\author{
Salwa Tashkandi ${ }^{\mathrm{a}, \mathrm{b}}$, Stanley M. Fergusson ${ }^{\mathrm{a}}$, Lijing Wang ${ }^{\mathrm{a}, *}$ \\ Sinnappoo Kanesalingam ${ }^{\mathrm{a}}$

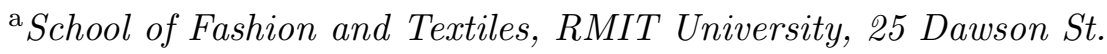 \\ Brunswick 3056, Melbourne, Australia \\ ${ }^{\mathrm{b}}$ Departments of Fashion and Textile, King Abdul Aziz University, Jeddah, Kingdom of Saudi Arabia
}

\begin{abstract}
An abaya is a traditional Muslim woman's outer garment. It is black and worn on a day-to-day basis when women are outside their homes. The abaya absorbs most of the heat from sunlight in a hot climate as it is black, making the wearer very uncomfortable. In order to reduce absorption of heat in an abaya and to make the wearer more comfortable, it is proposed that a treatment with a solar energy reflector could enable the wearer to perspire less; thus allowing them to feel cooler. This paper investigates the thermal comfort properties of plain-woven fabrics dyed in black and treated chemically to reflect a proportion of sunlight's energy. The fabrics were made from $100 \%$ wool and two polyester/wool blends. The testing results showed that the fabrics that had received the reflective treatment possessed marginally improved thermal comfort properties as compared to fabrics without the treatment.
\end{abstract}

Keywords: Abaya; Black Woven Fabric; Thermal Comfort; Air Permeability; Moisture Management

\section{Introduction}

Generally, garments provide protection from weather and enhance aesthetics [1]. Garments differ from region to region based on tradition as well as climatic conditions. The abaya (Fig. 1) is a traditional outer garment worn by some women in parts of the Islamic world including Turkey, North Africa and the Arabian Peninsula. Abaya is a very long cloak consisting of a large square of fabric draped from the shoulders or head. It covers the majority of the face and body and can be worn with the "niqab", a face veil covering everything but the eyes [2].

Most abayas are black as it is considered to be the most socially conservative way for women to dress in the Arabian Gulf. Considering the extreme climatic conditions in the Arabian Gulf region where the temperature in summer sometimes exceeds $45^{\circ} \mathrm{C}$, wearing an abaya can be very uncomfortable. Black fabrics are the most thermally uncomfortable to wear in hot climates

\footnotetext{
${ }^{*}$ Corresponding author.

Email address: lijing.wang@rmit.edu.au (Lijing Wang).
} 
due to the fact that darker fabrics absorb solar heat efficiently and this heat does not dissipate quickly [3]. Although many researchers have worked on the improvement of comfort performance in clothing $[1,4,5]$, to date limited research has been undertaken to assess and alter the thermal comfort properties of the abaya. In order to improve abaya comfort performance, it is necessary to reduce the heat absorption so that the wearer will perspire less and feel more comfortable.

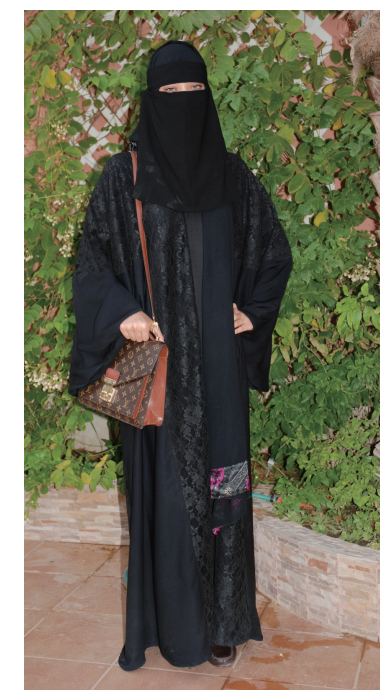

Fig. 1: Abaya and face veil in black colour

Generally, light coloured fabrics reflect both visible (colour) and invisible (heat) rays of sunlight. On the other hand, dark coloured fabrics absorb both types of radiation. The solar energy absorbing and retaining behaviour may be modified by incorporating a special chemical in fibre [6]. A treatment to textiles that reflects sun energy but without affecting the colour or feel of the fabric could be an effective solution for reducing thermal discomfort caused by wearing a black garment. Therefore, the present study aims at improving the thermal comfort properties of the traditional abaya by giving black fabrics for making the abaya an energy reflecting treatment.

Some investigators have reported that sweat can be readily absorbed by natural fibers, such as wool and cotton, and this improves the thermal comfort properties [7-9]. It has also been reported that synthetic fibers improved the comfort properties of fabrics as well [5, 10-12]. Blends of natural and manufactured fibres potentially have the advantage of combining the desirable properties of both fibre components, such as comfort, durability and easy-care properties [13]. Polyester/wool fabrics are commonly used in many textile applications to improve the above properties. Therefore, this research used three types of plain woven fabrics; pure wool and two different polyester/wool blends.

\section{Experimental}

Three plain-woven fabrics used in this study were $100 \%$ wool, $63 / 37$ polyester/wool (63/37 Pe/W) and 50/50 polyester/wool $(50 / 50 \mathrm{Pe} / \mathrm{W})$ as shown in Table 1 . After dyeing to a black colour, the fabrics were given an Energy Reflection Chemical (ERC) treatment. Fabric performance was then evaluated. 
Table 1: Structural and physical properties of the woven fabric samples

\begin{tabular}{cccccccc}
\hline $\begin{array}{c}\text { Fabric } \\
\text { composition }\end{array}$ & Sample & $\begin{array}{c}\text { Weave } \\
\text { structure }\end{array}$ & Ends/cm & Picks/cm & $\begin{array}{c}\text { Fabric } \\
\text { weight }\left(\mathrm{g} / \mathrm{m}^{2}\right)\end{array}$ & Thickness $(\mathrm{mm})$ & $\begin{array}{c}\text { Fabric } \\
\text { cover factor }\end{array}$ \\
\hline \multirow{3}{*}{$100 \%$ Wool } & Greige & & 25 & 22 & $148.4 \pm 0.9$ & $0.35 \pm 0.005$ & 19.74 \\
& Dyed Black & Plain & 26 & 23 & $164.8 \pm 0.8$ & $0.43 \pm 0.008$ & 20.32 \\
& ERC Treated & & 26 & 23 & $165.2 \pm 0.8$ & $0.43 \pm 0.009$ & 20.32 \\
\hline \multirow{5}{*}{$63 / 37 \mathrm{Pe} / \mathrm{W}$} & Greige & & 23 & 21 & $132.0 \pm 0.7$ & $0.34 \pm 0.005$ & 18.68 \\
& Dyed Black & \multirow{2}{*}{ Plain } & 24 & 22 & $146.4 \pm 0.6$ & $0.37 \pm 0.005$ & 19.30 \\
& ERC Treated & & 24 & 22 & $145.8 \pm 1.5$ & $0.37 \pm 0.005$ & 19.30 \\
\hline \multirow{5}{*}{$50 / 50 \mathrm{Pe} / \mathrm{W}$} & Greige & & 22 & 20 & $130.6 \pm 1.1$ & $0.34 \pm 0.007$ & 17.95 \\
& Dyed Black & \multirow{2}{*}{ Plain } & 23 & 21 & $146.8 \pm 1.3$ & $0.36 \pm 0.004$ & 18.58 \\
& ERC Treated & & 23 & 21 & $145.0 \pm 0.0$ & $0.36 \pm 0.005$ & 18.58 \\
\hline
\end{tabular}

\subsection{Dyeing}

\subsection{1 $100 \%$ Wool Fabric}

The dye bath used for wool fabric was stainless steel and electrically heated. The bath consisted of 25 litres of water at $40{ }^{\circ} \mathrm{C}, 2 \%$ ammonium sulphate on weight of fabric (o.w.f.), $0.75 \%$ Albegal SET (o.w.f.), and $0.5 \%$ acetic acid (o.w.f.). The fabric was treated in the above bath for 5 minutes. The $\mathrm{pH}$ of the bath was maintained at $\mathrm{pH} 4.4$. Then $4 \%$ of Isolan Black LS-LDN (o.w.f.) predissolved in water was added. While maintaining constant stirring, the bath temperature was raised to the boil, and boiling was continued for 30 minutes. An additional $0.75 \%$ acetic acid (o.w.f.) was added to clear the bath. Boiling was continued for a further 15 minutes. Following this, the bath was cooled to $60{ }^{\circ} \mathrm{C}$ by slowly adding warm water, and the samples were then rinsed at $40^{\circ} \mathrm{C}$. The dyeing cycle is shown as a line-diagram in Fig. 2.

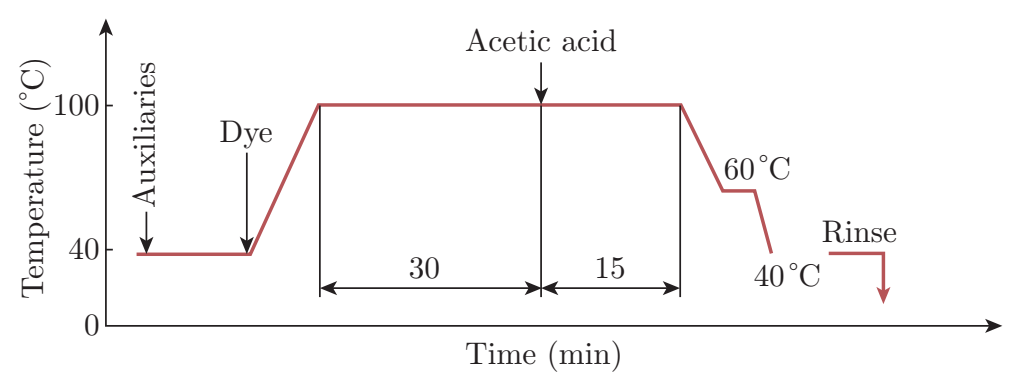

Fig. 2: Line diagram of wool fabric dyeing to black

One piece of the dyed $100 \%$ wool fabric was treated with ERC as follows. The treatment bath, consisted of 6 litres water, $4 \%$ o.w.f of the ERC, maintained at $\mathrm{pH}$ of 4 by the additional of acetic acidat $10 \%$ strength. The dyed fabric was introduced into the bath and the temperature was raised to $70-80{ }^{\circ} \mathrm{C}$ and kept for 15 minutes. The bath temperature was then lowered to ambient temperature. The treated fabric was rinsed, hydro extracted and dried. The treatment with ERC is shown as a line-diagram in Fig. 3. 


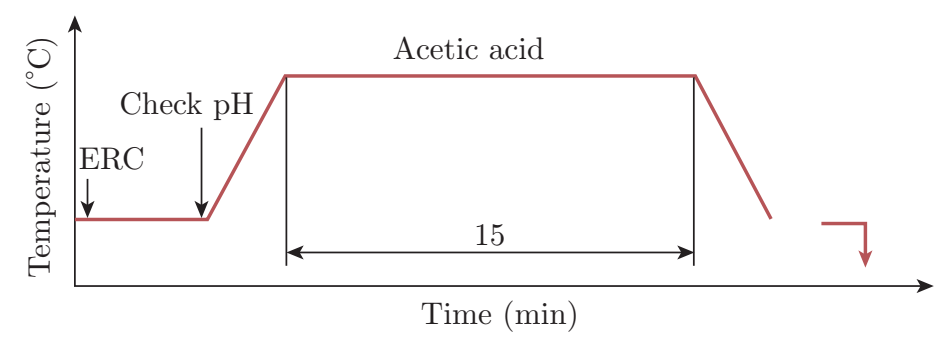

Fig. 3: Line diagram of treatment with the ERC

\subsubsection{Polyester/Wool Blends}

A different dyeing method was used for Pe/W blends. The polyester fibre must be dyed at a temperature exceeding $100{ }^{\circ} \mathrm{C}$. However, a dyeing temperature higher than $110{ }^{\circ} \mathrm{C}$ would cause degradation of wool fibre. A carrier and disperse dye were therefore used for polyester and wool uniform dyeing at $110{ }^{\circ} \mathrm{C}$. A Werner Mathis Lab high temperature HP Jumbo Jet JFO was used for the dyeing of the fabrics in a black colour and for treatment with the ERC. The dye bath was set at $40{ }^{\circ} \mathrm{C}$. After $5 \mathrm{~min}$, the completely dissolved auxiliaries (Albegal SET 0.5\% o.w.f. wool-level ling agent and Albegal FFC $1 \mathrm{~g} / \mathrm{l}$ defoaming agent) were added to the dye bath. Dyapol BD (2 $\mathrm{g} / \mathrm{l})$ as buffer and Optinol BTH $(2 \mathrm{~g} / \mathrm{l})$ were mixed and added to the dye bath. The mixture was added as a polyester carrier, and then $4 \%$ ERC was added. Finally, 2.5\% o.w.f. of Lanaset Black $\mathrm{B}$ and $1 \%$ Lanaset Grey were added.

Then the bath temperature was raised to $60{ }^{\circ} \mathrm{C}$ and $2 \%$ o.w.f. Foron Black RD-E dye was added. Following this addition, the temperature was raised to $110{ }^{\circ} \mathrm{C}$ at $1.5^{\circ} \mathrm{C}$ per minute and then dyeing was continued at $110^{\circ} \mathrm{C}$ for 45 minutes. After $20 \mathrm{~min}$ the $\mathrm{pH}$ was checked and adjusted to $4.8-5.0$ by addition of $0.5 \%$ acetic acid. The temperature was lowered to $70{ }^{\circ} \mathrm{C}$. The fabrics were rinsed twice using warm water at $50{ }^{\circ} \mathrm{C}$. Further treatment was performed using $3 \%$ ERC, $0.6 \%$ o.w.f. of $10 \%$ acetic acid in 9 litres of water at $75{ }^{\circ} \mathrm{C}$ and was maintained at $\mathrm{pH} 4$ for 15 min. Then rinsing was performed using warm water at $40{ }^{\circ} \mathrm{C}$. Samples were hydro extracted and then dried.

\section{$2.2 \quad$ Testing of Fabrics}

The fabric specimens were prepared and conditioned in the standard atmosphere of $20 \pm 2{ }^{\circ} \mathrm{C}$ and $65 \pm 2 \%$ Relative Humidity (R.H.) for at least 24 hours prior to testing.

\subsubsection{Physical Properties}

The physical properties of fabrics were assessed according to relevant standards, such as weight per unit area (AS 2001.2.13-1987) [14], thickness (AS 2001.2.15-1989) [15], thread count (ends and picks per unit length) (AS 2001.2.5-1991) [16] and cover factor [17]. Both untreated and treated samples were evaluated.

\subsubsection{Comfort Properties}

The thermal comfort properties (air permeability, thermal resistance, water vapour resistance and 
moisture management) of the fabrics were evaluated. Air permeability of the fabric was measured using an M021S air permeability tester from SDL ATLAS at a pressure difference of $100 \mathrm{~Pa}$. The EN ISO 9237 standard has been followed. All measurements were performed under standard atmospheric conditions. Five readings were taken for each of the fabrics with a test area of $5 \mathrm{~cm}^{2}$ and the mean airflow $\left(\mathrm{ml} / \mathrm{cm}^{2} / \mathrm{s}\right)$ and standard deviation were calculated.

A M259B Sweating Guarded Hot Plate instrument from SDL ATLAS as specified in ISO 11092: 1993 [18] was used to measure thermal resistance and water vapour resistance. The temperature of the guarded hot plate was kept at $35{ }^{\circ} \mathrm{C}$ (i.e. the temperature of human skin). From each fabric three specimens of $30 \times 30 \mathrm{~cm}$ were prepared and conditioned at $21^{\circ} \mathrm{C}$ and $65 \%$ R.H. for a minimum of 24 hours. For the determination of thermal resistance $\left(R_{c t}\right)$ of the fabrics, the standard atmospheric condition of $65 \%$ R.H. and $20{ }^{\circ} \mathrm{C}$ were set in the instrument. For determining the resistance to evaporative heat transfer $\left(\mathrm{R}_{\mathrm{et}}\right)$, the air temperature was set to $35{ }^{\circ} \mathrm{C}$ and the R.H. to $40 \%$. The air speed generated by the airflow hood was set to $1 \pm 0.05 \mathrm{~m} / \mathrm{s}$. The total vapour resistance of the fabric was measured and calculated after the system reached a steady state.

To compare the complete moisture management behaviour of samples, a Moisture Management Tester (MMT) from SDL ATLAS was used according to AATCC test method 195-2009. The MMT indices were used to determine the liquid moisture transport and distribution properties of the fabric samples. They are wetting time (top-bottom), absorption rate (top-bottom), maximum wetted radius (top-bottom), spreading speed (top-bottom), Accumulative One-way Transport Capacity Index (AOTI) and Overall Moisture Management Capability (OMMC) of fabrics. The top fabric surface is the surface in contact with the skin and the bottom surface is the other side of the fabric. Five specimens were tested and an average value and standard deviation for each sample were calculated. The MMT apparatus is based on the physical principle that the surface contact electrical resistance of a fabric changes with the content of a water-based liquid solution near the surface [19-22]. To simulate sweating, a special solution (synthetic sweat) was prepared and the same quantity of solution $(0.15 \mathrm{~g})$ was injected onto each specimen's top surface automatically by the MMT. The testing time was 2 minutes.

\section{Results and Discussion}

The results in Table 1 indicate that the fabric weight and thickness increased due to shrinkage of the fabrics during dyeing and ERC treatment. For $100 \%$ wool fabric, though treatment with the ERC increased the fabric weight and thickness when compared to the dyed fabric, the fabric cover factor remained the same. The black dyed and ERC treated samples had approximately similar weights, thicknesses and cover factors for both 63/37 Pe/W and 50/50 Pe/W fabrics. Overall, the ERC treatment did not significantly affect the physical properties of the dyed fabrics.

\subsection{Air Permeability}

Air permeability is the measure of airflow per unit area through a fabric perpendicular to the fabric plain. This parameter to a large extent influences the thermal comfort properties of the fabrics. The air permeability values in Fig. 4 show that the greige fabrics had a higher air permeability value than the dyed fabric with or without ERC. This could be because the structure of the 
greige fabric was more open. After dyeing and ERC treatment the fabrics had more compact structures due to relaxation shrinkage, resulting in lower air permeability. Compared with the Pe/W fabrics, the 100\% wool fabric showed lower air permeability due to its higher cover factor, weight and thickness as shown in Table 1. For all fabrics, the air permeability after treatment with the ERC remained the same level compared to their dyed counterparts. The decrease in the air permeability of $\mathrm{Pe} / \mathrm{W}$ blends after dyeing and the ERC treatment could be attributed to the higher shrinkage of the Pe/W blends as indicated by the increase of the fabric cover factor. Overall, air permeability differences between each of the dyed fabrics treated with and without the ERC were not statistically significant at $95 \%$ confidence intervals.

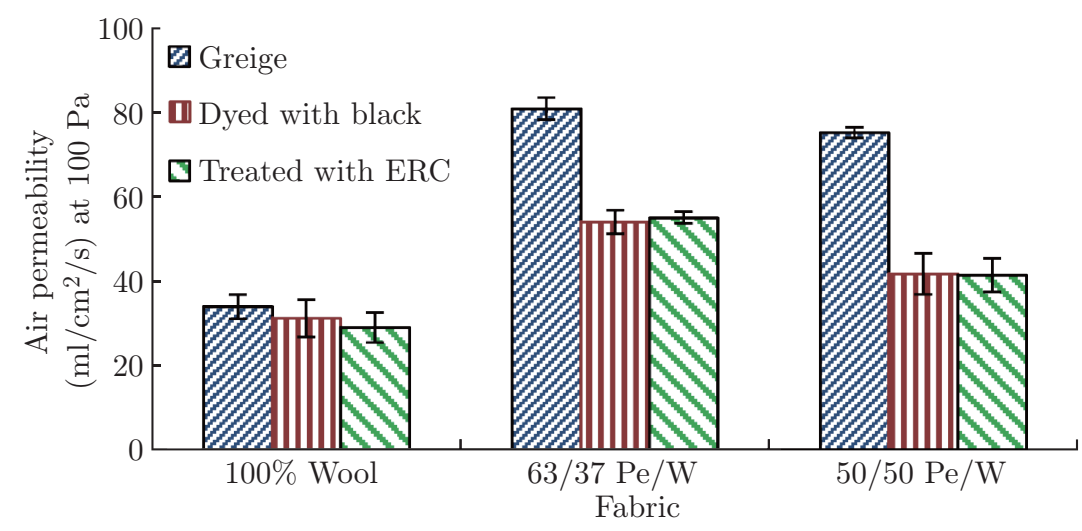

Fig. 4: Comparison of air permeability

\subsection{Thermal Resistance $\left(\mathbf{R}_{\mathrm{ct}}\right)$}

Thermal resistance results are graphically shown in Fig. 5. The $\mathrm{R}_{\mathrm{ct}}$ values of all the greige fabrics lie in a close range. It can be observed that all greige fabrics hada similar level of $\mathrm{R}_{\text {ct }}$. After dyeing and ERC treatment, the fabric containing 50/50 Pe/W had the lowest value of $\mathrm{R}_{\mathrm{ct}}$ when compared with the other fabrics. This may have been due to the lower fabric thickness that is a major factor affecting thermal resistance. The fabrics with $\mathrm{R}_{\mathrm{ct}}$ values less than 0.055 are considered to be very comfortable. Hence, these fabrics are considered to be comfortable. The higher values of $\mathrm{R}_{\mathrm{ct}}$ for $63 / 37 \mathrm{Pe} / \mathrm{W}$ can be attributed to the higher amount of polyester content in the fabric. The increase in the $R_{\text {ct }}$ values can be attributed to the increase in the fabric thickness after dyeing and ERC treatment. For a hot environment, low thermal resistance is necessary to allow the heat from the body to flow outside to the environment [23]. On the other hand, high thermal resistance may help in reducing the amount of energy from sunlight, which is transferred to the body in an extremely hot environment.

\subsection{Water Vapour Resistance $\left(\mathbf{R}_{\mathrm{et}}\right)$}

A lower water vapour resistance value is desirable for better moisture transport properties of the fabric leading to improvement in thermal comfort [24]. It can be observed in Fig. 6 that the $\mathrm{R}_{\text {et }}$ of the $63 / 37 \mathrm{Pe} / \mathrm{W}$ fabric was the lowest among the fabrics examined after dyeing and ERC treatment. The $\mathrm{R}_{\text {et }}$ of the $100 \%$ wool sample was the highest due to the fact that it was the thickest and heaviest fabric among the three fabrics studied. The fabrics with $\mathrm{R}_{\text {et }}$ values for all 


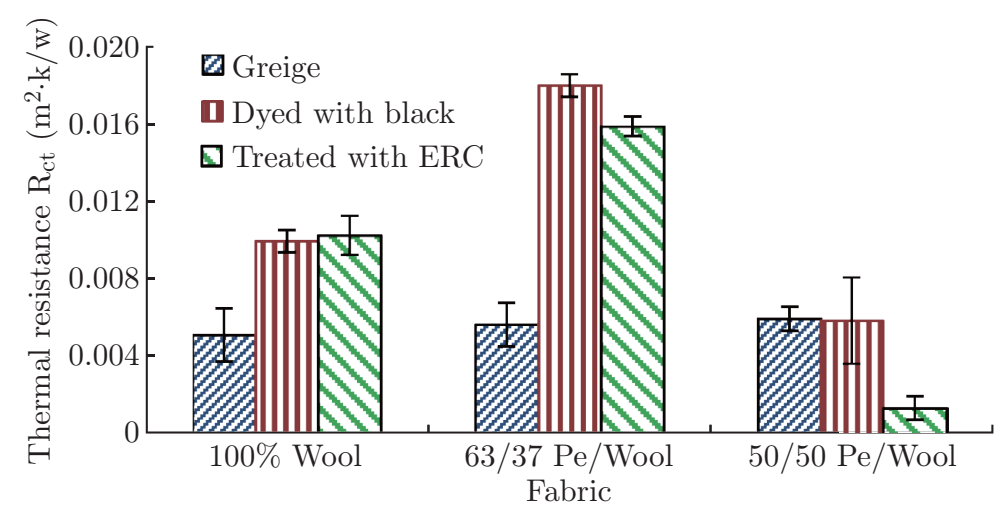

Fig. 5: Comparison of thermal resistance $R_{\mathrm{ct}}$

fabrics are between the range (0-4), which is considered to be very good or extremely breathable and comfortable according to Hohenstein institute. Hence, these fabrics are considered to be comfortable. The higher values of $\mathrm{R}_{\mathrm{et}}$ for $100 \%$ wool can be attributed to the higher amount of wool content in the fabric. The increase in the $R_{\text {et }}$ values can be attributed to the increase in the fabric thickness after dyeing and ERC treatment. A higher value of water vapour resistance indicated that the fabric would have a lower rate of water vapour transmission from a body to the outside atmosphere. As far as water vapour resistance was concerned, there was no statistical significance between dyed fabrics with and without the ERC treatment.

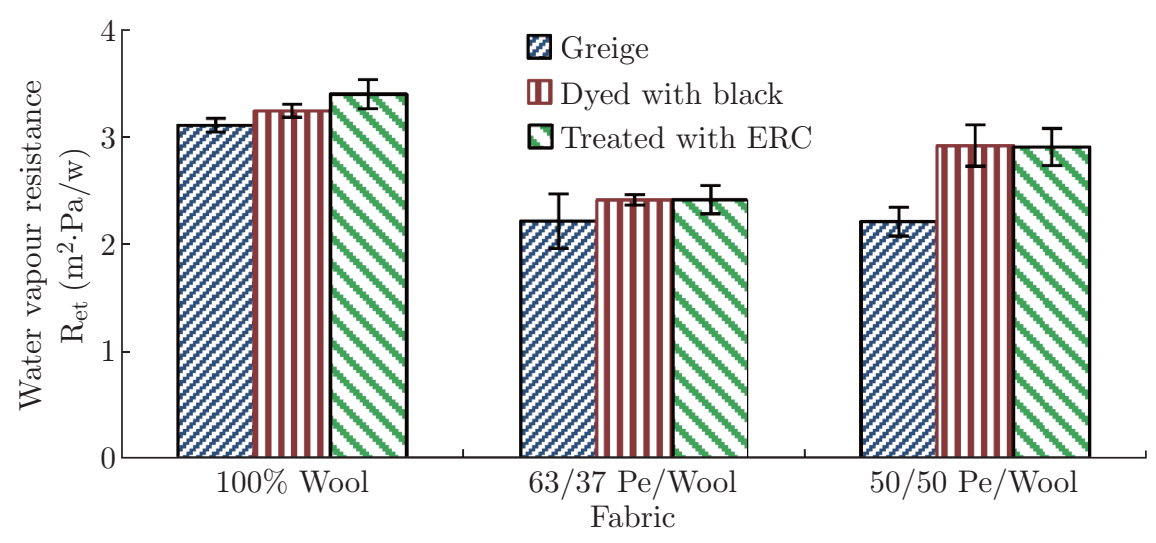

Fig. 6: Comparison of water vapour resistance $R_{e t}$

\subsection{Moisture Management Properties}

The moisture management properties of the fabrics are given in values in Table 2 . The results show that all samples had the same level of moisture management performance irrespective of having been dyed or given an energy reflective treatment. The $100 \%$ wool fabric, after being dyed black, had a lower top surface absorption rate than the ERC treatment, although the maximum wetted radii for top and bottom surfaces were the same. The small max wetted radius indicates that the testing solution did not spread much during the 2 minute testing duration.

The $100 \%$ wool has poor liquid moisture management capacity grade and a poor AOTI. These fabrics had a very slow spreading rate on both top and bottom surfaces. This was due to the 
Table 2: Moisture management data

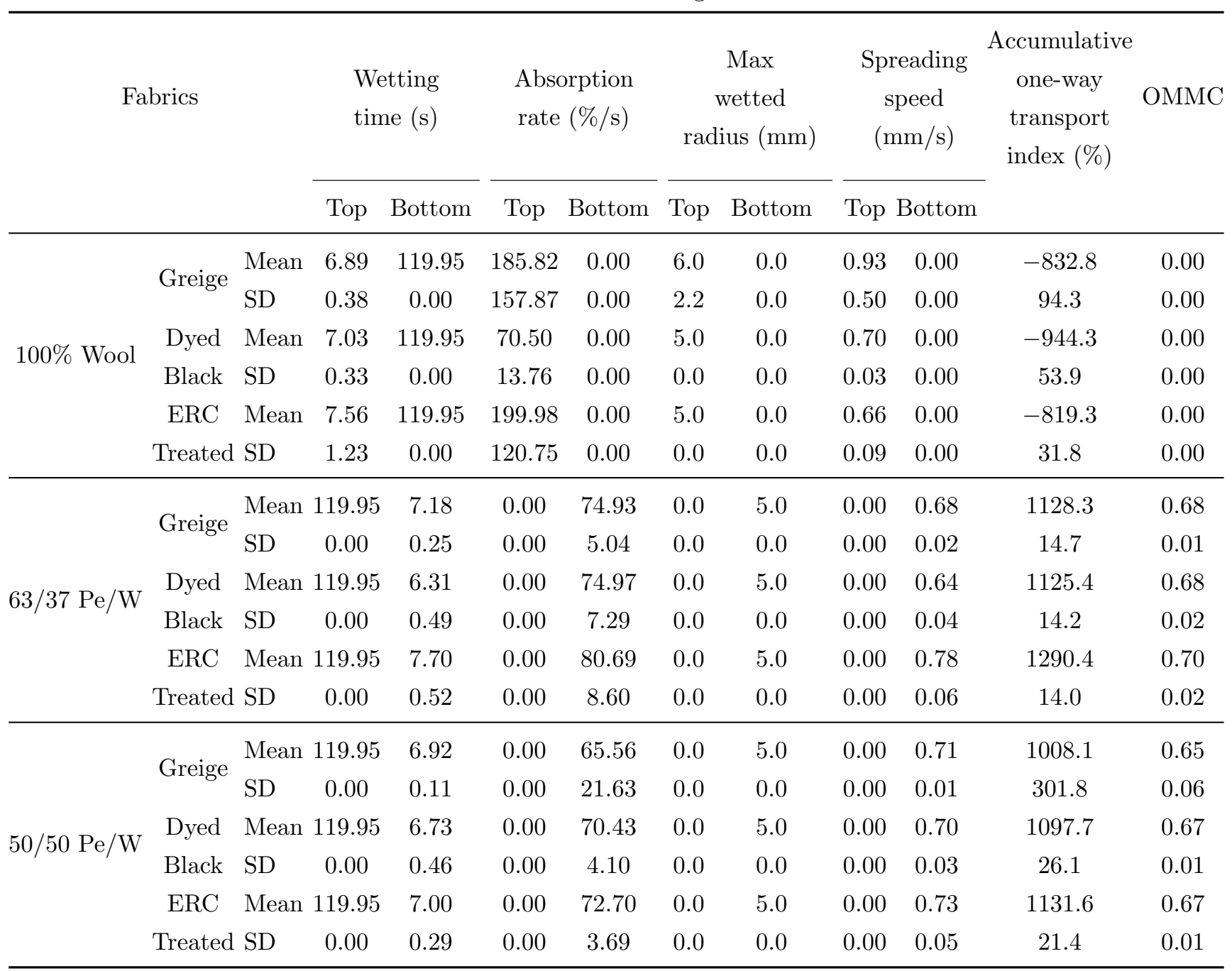

Note: $\mathrm{SD}=$ Standard Deviation

hydrophobic nature of the wool fibre. There was medium wetting time on top surface but slow wetting time on bottom surface. This may be because $100 \%$ wool fabric was thicker and has a higher cover factor. Therefore, it took long time for liquid moisture to spread on the outer fabric surface. The higher indices on the top surface than the bottom surface mean that the moisture remained at the top of the fabric surface near the skin but was not transported to the bottom of the fabric surface.

The $\mathrm{Pe} / \mathrm{W}$ (50/50 and 63/37) blended fabrics had a high capability of managing the transport of liquid moisture compared to the $100 \%$ wool. They had an excellent AOTI. This means that the moisture content of the bottom surface was higher than the moisture content of the top surface, and the difference of the accumulative moisture content between the two surfaces of the fabric was high. The wetting time and absorption rate were slow on the top surface, while the wetting time and absorption rate were fast on bottom surface. This suggests that the bottom surface of the fabric started to get wet faster than the top surface. As the bottom surface absorbed more moisture than the top surface, the top surface remained drier than the bottom surface. Because the wetting time and absorption on the bottom surface was higher than the top, the water was transported from the top to the bottom surface and the top surface would remain dry. 
Nevertheless, both fabric top and bottom surfaces had a very slow water spreading speed.

According to the result, the $100 \%$ wool fabric can be classified as a waterproof fabric, since the fabric had very slow rate of water absorption, a low spreading speed, no one way transport, and no water penetration. The blend fabrics can be classified as fabric through which water can penetrate, because they have small spreading area and excellent one-way transport indices. Therefore, the blend fabrics had better moisture management performance than $100 \%$ wool and should be more comfortable to wear in hot climates.

Fibre blending plays an important role in moisture related comfort properties of clothing. Though wool has superior moisture absorbing capability compared to polyester, it took long time for liquid moisture to spread on wool fabric surface as well as transport through the fabric due to the nature of wool hydrophobicity. Hence wool did not show good moisture management capability during the two minute MMT test. On the other hand, due to the plain woven fabric structure, wool component and high yarn coverage (fabric cover factor is around 19), the overall moisture management performance of polyester wool fabrics did not reach the excellent rating level. Hence further study is warranted for better fabric design and understanding of moisture management performance.

Since the purpose for ERC treatment is to reduce radiation heat, tests of quantifying material infrared (IR) radiation characteristics will provide more useful information for the effectiveness of ERC treatment. Hu et al. [25] recently developed an instrument for measuring thermal radiation properties of polymeric materials. To further this work, similar IR characterization techniques will be employed to evaluate IR radiation properties. In addition, further research is being conducted to set the testing temperature above $35^{\circ} \mathrm{C}$, which is more close to realistic extreme climatic conditions in the Arabian Gulf region. The results will be reported in our future publications.

\section{Conclusion}

The main objective of this research was to investigate the effect of applying an energy reflection chemical treatment on abaya fabrics typically dyed to a black colour. The experimental results showed that after giving the abaya fabrics energy reflecting treatment, the thermal comfort properties were marginally improved under the experimental conditions examined. For air permeability and water vapour resistance, there were no statistically significant differences at 95\% confidence intervals between dyed fabrics with and without the treatment. However, the blended fabrics (50/50 polyester/wool fabric and 63/37 polyester/wool fabric) showed improved water vapour resistance and moisture management performance. Though further work is being conducted to investigate the energy reflection treatment effects, it was also concluded that the black polyester/wool blend fabrics appear to be thermally more comfortable than the 100\% wool fabric especially after an energy reflection chemical treatment.

\section{Acknowledgement}

We express our sincere gratitude and thanks to the Government of Kingdom of Saudi Arabia and King Abdul-Aziz University for providing a PhD Scholarships to the first author. 


\section{References}

[1] Song G. Improving comfort in clothing. (1st ed.). Philadelphia: Woodhead Publishing Ltd, 2011

[2] Tashkandi S, Wang L, Kanesalingam S. An investigation of thermal comfort properties of abaya woven fabrics. Journal of The Textile Institute 2013; DOI: 10.1080/00405000.2012.758351: 1-8

[3] Nielsen B. Solar heat load: Heat balance during exercise in clothed subjects. Europ. J. Appl. Physiol. 1990; 60: 452-456

[4] Prakash C, Ramakrishnan G, Koushik CV. A study of the thermal properties of bamboo knitted fabrics. Journal of Thermal Analysis and Calorimetry 2012; 111: 101-105

[5] Yoon H, Sawyer L, Buckley A. Improved comfort polyester: Part II: Mechanical and surface properties. Textile Research Journal 1984; 54: 357-365

[6] Furuta T, Shimizu Y, Kondo Y. Evaluating the temperature and humidity characteristics of a solar energy absorbing and retaining fabric. Textile Research Journal 1996; 66: 123-130

[7] Naebe M, Lutz V, McGregor B, Tester D, Wang X. Effect of surface treatment and knit structure on comfort properties of wool fabrics. Journal of The Textile Institute 2013; 104: 600-5

[8] Naebe M, Lutz V, McGregor B, Tester D, Wang X. Predicting comfort properties of knitted fabrics by assessing yarns with the wool comfortmeter. Journal of The Textile Institute 2013; 104: 628-33

[9] Wang G, Zhang W, Postle R, Phillips D. Evaluating wool shirt comfort with wear trials and the forearm test. Textile research journal 2003; 73: 113-119

[10] DeMartino R, Yoon H, Buckley A. Improved comfort polyester: Part V: Results from two subjective wearer trials and their correlation with laboratory tests. Textile Research Journal 1984; 54: 602-613

[11] Demartino RN. Comfort properties of polybenzimidazole fiber. Textile Research Journal 1984; 54: 516-521

[12] Yoon H, Buckley A. Improved comfort polyester. Textile Research Journal 1984; 54: 289-298

[13] Prakash C, Ramakrishnan G. Effect of blend ratio, loop length, and yarn linear density on thermal comfort properties of single jersey knitted fabrics. International Journal of Thermophysics 2013; 34: $113-121$

[14] As 2001.2.13-1987, Determination of mass per uint area and mass per length of fabrics

[15] As 2001.2.15-1989, Determination of thickness of textile fabrics

[16] As 2001.2.5-1991, Determination of the number of threads per unit length in woven fabric

[17] Booth. JE. Principles of textile testing. (third ed.). London Newnes-Butterworths, 1968

[18] ISO 11092: 1993 (E), Physiological effects- Mesurment of thermal nad water-vapour resistance under steady state condition (sweating gurded hotplate)

[19] Marler JW, Baxter P. The 2003 Australian wool innovation on-farm fibre measurement instrument evaluation trial, Part 1: Accuracy and precision trials. Wool Technology and Sheep Breeding 2004; 52: $43-96$

[20] Bedek G, Salaün F, Martinkovska Z, Devaux E, Dupont D. Evaluation of thermal and moisture management properties on knitted fabrics and comparison with a physiological model in warm conditions. Applied ergonomics 2011; 42: 792-800

[21] Hu J, Li Y, Yeung K-W, Wong AS, Xu W. Moisture management tester: A method to characterize fabric liquid moisture management properties. Textile Research Journal 2005; 75: 57-62

[22] Prakash C, Ramakrishnan G, Koushik C. Effect of blend proportion on moisture management characteristics of bamboo/cotton knitted fabrics. Journal of The Textile Institute 2013; DOI: 10.1080/00405000.2013.800378: 1-7 
[23] Das A, Kothari V, Sadachar A. Comfort characteristics of fabrics made of compact yarns. Fibers and Polymers 2007; 8: 116-122

[24] Fan J, Tsang HWK. Effect of clothing thermal properties on the thermal comfort sensation during active sports. Textile Research Journal 2008; 78: 111

[25] Hu JY, Li Y, Yeung KW, Wang SX. Characterization of thermal radiation properties of polymeric materials. Polym. Test. 2006; 25: 405-412 